\title{
A CHARACTERIZATION OF MATRIX
}

\section{INEQUALITY $A \geqslant B \geqslant C$ VIA KARCHER MEAN}

\section{JIAN SHI AND SIYUAN SHEN}

Abstract. Let $A, B$ and $C$ be three positive definite matrices. In this paper, we show a characterization of $A \geqslant B \geqslant C$ via the Karcher mean as follows,

$$
\begin{aligned}
& \Lambda\left(\omega ; A^{-p_{1}}, B^{-p_{2}}, B^{t} \bigsqcup_{s} C^{p_{3}}\right) \leqslant C, \\
& \Lambda\left(\omega ; C^{-p_{1}}, B^{-p_{2}}, B^{t} \bigsqcup_{s} A^{p_{3}}\right) \geqslant A
\end{aligned}
$$

hold for $t \in[0,1], s \geqslant 1, p_{1}, p_{2}>0$ and $p_{3}>1$, where $\hat{\omega}=\left(\frac{1}{p_{1}+1}, \frac{1}{p_{2}+1}, \frac{2}{\left(p_{3}-t\right) s+t-1}\right), \omega=$ $\left(w_{1}, w_{2}, w_{3}\right)=\frac{\hat{\omega}}{\|\hat{\omega}\|_{1}}$.

Mathematics subject classification (2010): 15A45, 47A63.

Keywords and phrases: Positive definite matrix, matrix inequality, Karcher mean.

\section{REFERENCES}

[1] T. Ando, C. K. Li And R. Mathias, Geometric means, Linear Algebra Appl., 385 (2004), 305334.

[2] R. Bhatia AND J. HolbRook, Riemannian geometry and matrix geometric means, Linear Algebra Appl., 413 (2006), 594-618.

[3] R. Bhatia, Positive definite matrices, Princeton Ser. Appl. Math., Princeton University Press, Princeton, NJ, 2007.

[4] M. Ito, Matrix inequality including grand Furuta inequality via Karcher mean, J. Math. Inequal., 2 (2014), 279-285.

[5] J. D. LAWSOn And Y. Lim, Monotonic properties of the least squares mean, Math. Ann., 351 (2011), 267-279.

[6] J. D. LAwSON AND Y. Lim, Karcher means and Karcher equations of positive definite operators, Trans. Amer. Math. Soc., Series B, 1 (2014), 1-22.

[7] Y. LIM AND M. PÁLFIA, Matrix power menas and Karcher mean, J. Funct. Anal., 262 (2012), 14981514.

[8] C.-S. Lin AND Y. J. CHO, Characterizations of operator inequality $A \geqslant B \geqslant C$, Math. Inequal. Appl., 14 (2011), 575-580.

[9] M. MOAKHER, A differential geometric approach to the geometric mean of symmetric positive-definite matrices, SIAM J. Matrix Anal. Appl., 26 (2005), 735-747.

[10] M. UChiYAmA, Criteria for operator means, J. Math. Soc. Japan, 55 (2003), 197-207.

[11] T. YAMAZAKI, The Riemannian mean and matrix inequalities related to the Ando-Hiai inequality and chaotic order, Oper. Matrices, 3 (2012), 577-588.

[12] T. YAMAZAKI, An elementary proof of arithmetic-geometric mean inequality of the weighted Riemannian mean of positive definite matrices, Linear Algebra Appl., 438 (2013), 1564-1569.

[13] J. YUAN AND C. WANG, Riccati type operator equation and Furuta's question, Math. Inequal. Appl., 4 (2014), 1337-1342. 